\title{
Biosynthesis of Silver Nanoparticles from Allium ampeloprasum Leaves Extract and Its Antifungal Activity
}

\author{
Samiyah Saeed Al-Zahrani',2, Saleh Mohammed Al-Garni ${ }^{1}$ \\ ${ }^{1}$ Department of Biology, Faculty of Science, King Abdulaziz University, Jeddah, KSA \\ ${ }^{2}$ Department of Biology, Faculty of Arts and Science, Albaha University, Albaha, KSA \\ Email: sshassan@bu.edu.sa
}

How to cite this paper: Al-Zahrani, S.S. and Al-Garni, S.M. (2019) Biosynthesis of Silver Nanoparticles from Allium ampeloprasum Leaves Extract and Its Antifungal Activity. Journal of Biomaterials and $\mathrm{Na}$ nobiotechnology, 10, 11-25.

https://doi.org/10.4236/jbnb.2019.101002

Received: December 21, 2018

Accepted: January 21, 2019

Published: January 24, 2019

Copyright (C) 2019 by author(s) and Scientific Research Publishing ISnc. This work is licensed under the Creative Commons Attribution International License (CC BY 4.0).

http://creativecommons.org/licenses/by/4.0/

\begin{abstract}
Development of natural based nanomaterial immense interest of researchers involved in eco-friendly biosynthesis of nanoparticles. This research set out to investigate the potential of Allium ampeloprasum leaves extract to synthesize silver nanoparticles (AgNPs), and evaluate their antifungal activity against some toxigenic strains of Aspergillus isolates. In order to achieve this, AgNPs were prepared using plant extracts at room temperature and the formation of AgNPs was visually detected after the color changed to dark brown within few minutes. The biosynthesized AgNPs were characterized using the UV-vis spectroscopy, which confirmed the formation of AgNPs with a maximum peak at $437 \mathrm{~nm}$ due to the Plasmon resonance. The main active reduction agents were detected by Fourier Transmission infrared spectroscopy (FTIR). Also, the nanoparticles were characterized using Scanning electron microscope (SEM). The antifungal activity of AgNPs was investigated by agar well diffusion method, which revealed inhibition zones of $8 \mathrm{~mm}, 10 \mathrm{~mm}, 11 \mathrm{~mm}$, $11 \mathrm{~mm}$ and $14 \mathrm{~mm}$ against Aspergillus flavus 1, A. parasiticus, A. flavus 2, A. ochraceus, and $A$. niger. The minimum inhibition concentration (MIC) was determined using micro broth dilution method. MIC values of AgNPs ranged from $652-2500 \mu \mathrm{g} / \mathrm{ml}$. The fungi treated with AgNPs, were examined with (SEM), it was observed that the treated fungi were damaged. These results suggest that AgNPs have the potential to be used as an ideal eco-friendly approach to control toxigenic fungi.
\end{abstract}

\section{Keywords}

Silver Nanoparticles, Antifungal, AgNPs, Aspergillus, Allium ampeloprasum 


\section{Introduction}

Toxigenic fungi pose significant health hazards to humans and animals worldwide. These toxigenic fungi contaminate food products and produce mycotoxins as secondary metabolites, such as Aspergillus species which is considered as the most significant producers of mycotoxins [1] [2] [3] [4].

Mycotoxins are considered as an important reason for the illness of human as well as farm animals around the world. Hence, the control of toxin producers is a matter of importance. Anti-fungal agents have been utilized for a long time to eliminate these fungi with less damage to the host [5]. However, the issue of fungal resistance and health hazard due to exposure to chemical fungicides is a major concern. Hence, there is an utmost need to develop some ideal alternative antifungal agents. Recently, studies have been carried out to circumvent this issue by developing new technologies to control the contaminant fungi such as using metal nanoparticles as antimicrobial agents [6] [7] [8].

Currently, nanotechnology has framed the premise of numerous applications and showed the high effectiveness of metal nanoparticles as antimicrobial agents besides their applications in medicine and pharmaceuticals field [9] [10]. Recent studies have shown that among the metal nanoparticles, silver nanoparticles (AgNPs) ideally hold great promise as antifungal agents against fungal species like Aspergillus fumigates [11] and against $A$. flavus, $A$. niger and $A$. fumigatus [12].

Extensive methodologies have been developed for synthesis of AgNPs biologically using natural sources such as plants parts and microorganisms. Lately, researchers have been exploiting the plant capability for biosynthesis of AgNPs. Green synthesis of nanoparticles is a term given to synthesis of (NPs) by biologically active compounds of plant origin. Since plants are a rich source of vast bioactive compounds such as flavonoids, tannins, terpenoids, and alkaloids and are capable of enhancing the synthesis of AgNPs in the cost-effective and eco-friendly manner [13]. Almost 50 types of plant origin extracts demonstrated the capability of biosynthesis of AgNPs. Also, the naturally synthesized AgNPs from plant extracts of (leave, roots, stems and seeds) were utilized as a part of conventional antimicrobials which can be productive assets for new antifungal agents [14].

Thus, this study was aimed to investigate the capability of leaves extract of $\mathrm{Al}$ lium ampeloprasum in biosynthesis of AgNPs and characterize the AgNPs. Moreover, the antifungal activities of the synthesized AgNPs were evaluated against some Aspergillus strains.

\section{Methodology}

\subsection{Plant Collection, Identification and Preparation of Leaves Extract}

Fresh leaves of Allium ampeloprasum were purchased from the local stores, in Jeddah, KSA. The collected leaves were thoroughly washed under running tap 
water three times to remove debris and other contaminated organic contents, followed by distilled water and air dried on filter papers at room temperature in the shade. Then, the dried plant leaves were ground with an electrical grinder (Moulinex super blender) and stored in airtight containers [15]. $125 \mathrm{~g}$ of dried leaves were soaked in $500 \mathrm{ml}$ of $99 \%$ methanol by maceration at laboratory temperature. The supernatant was filtered with filter paper Whatman's No.1 and the solvent was evaporated under reduced pressure at $45^{\circ} \mathrm{C}$ using a rotavapor (EYELA Rotary Evaporator N-1001S-W) until dryness. The residue was finally suspended with $1 \mathrm{ml}$ of DMSO and stored in sterile amber bottles and kept at $4^{\circ} \mathrm{C}$ until used [16].

\subsection{Biosynthesis of Silver Nanoparticles (AgNPs)}

$100 \mathrm{mM}$ of silver nitrate was prepared in $100 \mathrm{ml}$ of deionized water and stored in an amber bottle to minimize the amount of light and kept in the refrigerator until use. Silver nanoparticles biosynthesized by adding $1 \mathrm{ml}$ of previously prepared methanolic plant extract to $99 \mathrm{ml}$ of deionized water containing $0.5 \mathrm{ml}$ of Triton $\mathrm{X}-100$. Then the extract was filtered using Millipore syringe filter with $0.22 \mu \mathrm{m}$ pore size and $1 \mathrm{ml}$ of $\mathrm{AgNO}_{3}(100 \mathrm{mM})$ was dissolved in $99 \mathrm{ml}$ of plant extract. The resulting solution was kept at room temperature until color changing to honey brown or dark color changed [17] [18].

\subsection{Characterization of AgNPs}

\subsubsection{UV-Visible Light Spectroscopy Analysis}

After the change of solution color, absorption spectral analysis was done by pipetting about $1 \mathrm{ml}$ of the AgNPs solution into UV quartz cuvette cell and monitored in $6715 \mathrm{UV} / \mathrm{V}$ is spectrophotometer in room temperature at the wavelength between 300 and $600 \mathrm{~nm}$ at a resolution of $1 \mathrm{~nm}$ and deionized water as a blank.

\subsubsection{Scanning Electron Microscope (SEM) of AgNPs}

Nanoparticles morphology was observed by scanning electron microscopy. The analysis was carried out after centrifugation of AgNPs solution at $4000 \mathrm{rpm}$ for $30 \mathrm{~min}$. The filtrate was discarded and the pellet was dried at $45^{\circ} \mathrm{C}$ in the oven to avoid any changes in the shape of nanoparticles. After drying, a small portion of the dried pellet was placed on carbon conductive tape for preparation to examine the morphology and elemental analysis using Scanning Electron Microscope (JEOL, JSM7600F).

\subsubsection{Fourier-Transform Infrared Spectroscopy (FTIR)}

The characterization of functional groups on the surface AgNPs of $A$. ampeloprasum extract before and after the reduction of $\mathrm{AgNO}_{3}$ were investigated. The solution was centrifuged at $7800 \mathrm{rpm}$ for $30 \mathrm{~min}$, the filtrate was discarded and the pellet was re-dispersed with sterilized distilled water. The centrifugation and re-dispersion was repeated three times to ensure the purification of nanoparticles. After the last centrifugation, the filtrate was discarded and the pellet was placed in freeze drying system (LABCONCO FreeZone 4.5) until dried up com- 
pletely. A small portion of the dried powdered samples was placed in the sample area of FTIR spectroscopy (IRAffinity-1, Shimadzu, Japan) and the spectra was scanned in the range of $500-4000 \mathrm{~cm}^{-1}$ at a resolution of $20 \mathrm{~cm}^{-1}$ in transmittance mode.

\subsection{Antifungal Activity}

\subsubsection{Determination of Antifungal Activity of AgNPs}

AgNPs solution and $A$. ampeloprasum extract were tested against five fungal isolates (A. flavus (ATCC 16875), A. flavus (ATCC 11498), A. ochraceus (ATCC 22947), A. parasiticus (ATCC 15517) and A. niger (ATCC 16404). These fungal strains were purchased from Cairo Microbiological Resources Centre, Faculty of Agriculture, Ain Shams University. $100 \mu$ of the tested solutions were added in wells of $6 \mathrm{~mm}$ diameters in PDA plates which were inoculated previously by spreading a freshly prepared fungal inoculum by using sterile cotton swabs over the entire agar surface and left for $60 \mathrm{~min}$ at laboratory temperature. The plates were left for 60 minutes at laboratory temperature to allow proper diffusion of each extract to the medium. The plates were further incubated at $25^{\circ} \mathrm{C}$ for 5 to 7 days. The experiment was performed in triplicates [19] [20].

The Minimum inhibitory concentration of AgNPs solution was carried out using Broth microdilution method against all fungal isolates [21]. The microtiter plates were incubated at $28^{\circ} \mathrm{C}$ for $5-7$ days in the shaking incubator. The MIC results determined by changing in optical density of the broth or by using an ELISA reader. Presence of clear PD broth with no density indicates the MIC.

\subsubsection{Examination of Fungal Morphological Changes by (SEM)}

Small agar pieces were cut out from the inhibition zone after 7 days' incubation periods, fixed for 3 hours in $2.5 \%(\mathrm{v} / \mathrm{v})$ glutaraldehyde $(100 \mathrm{mM})$ phosphate buffer solution ( $\mathrm{pH}$ 7.2) and then fixed in $1 \%(\mathrm{w} / \mathrm{v})$ osmium tetroxide $\left(\mathrm{O}_{\mathrm{S}} \mathrm{O}_{4}\right)$ for an hour. The agar blocks were dehydrated in a graded series of methanol and methanol: isoamylacetate $\left(\mathrm{C}_{7} \mathrm{H}_{14} \mathrm{O}_{2}\right)$. The specimens were dried with a critical point drier using liquid Carbon dioxide $\left(\mathrm{CO}_{2}\right)$ and coated with gold-coater for 5 minutes. The coated samples were observed under JSM-5600 LV with accelerating voltage of $10 \mathrm{kV}[22]$.

\section{Results and Discussion}

\subsection{Biosynthesis of Silver Nanoparticles}

Biosynthesis of silver nanoparticles was carried out by using plant extracts as bioactive agents which may reduce $\mathrm{AgNO}_{3}$ to $\mathrm{Ag}$ nanoparticles. The biosynthesis of AgNPs was determined visually by change in the color of the plant extract after adding $\mathrm{AgNO}_{3}$. As shown in "Figure 1" the color changing occurred after few minutes of incubation at room temperature, from pale yellow to honey brown color for AgNPs solution compared to the plant extract solution. The change in color is a manifestation of the formation of nanoparticles. The formation 


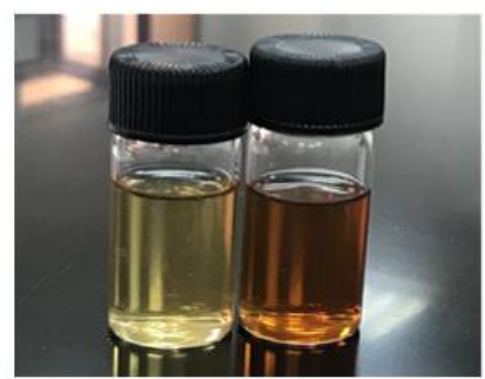

Figure 1. Biosynthesis of silver nanoparticles (right) from Allium ampeloprasum extract (left).

of different shades of color, including yellow and honey brown to dark brown AgNPs are widely reported in the literature [23] [24] [25] [26].

\subsection{AgNPs Characterization}

\subsubsection{Ultraviolet-Visible Light Spectroscopy}

The results of ultraviolet-visible light spectroscopy analysis showed the maximum absorption peak that occurred at the wavelength of $437 \mathrm{~nm}$ which refers to silver nanoparticles formation from $A$. ampeloprasum extract as shown in "Figure 2". This wavelength raised due to the surface Plasmon resonance of the particles. The A. ampeloprasum AgNPs UV absorption peak was similar to AgNPs UV absorption peak $437 \mathrm{~nm}$ obtained by Erythrina indica root [27] and agreed with the uv-vis results of $\operatorname{AgNPs} A$. Ampeloprasum prepared from aqueous leaf extract [28]. The results agreed with the statement of Sastry et al., (1997) that AgNPs exhibit a maximum UV-visible absorption in the range of 400 - $500 \mathrm{~nm}$ because of surface plasmon resonance [29].

\subsubsection{SEM Examination of AgNPs}

Scanning electron microscope (SEM) analysis was used in this work to observe the size and morphology of nanoparticles by electron charge oscillation principle in silver nanoparticles that exhibit by light [30]. The results of SEM analysis in "Figure 3" show that silver nanoparticles were found to be spherical in shape and were aggregated. This is in concordance with SEM analysis results of synthesized AgNPs using fruit extract of Momordica cymbalaria [31], Lippia nodiflora leave extract AgNPs [32] and Plectranthus zeylanicus leaf extract AgNPs [33]. This aggregation in silver nanoparticles may be due to secondary metabolites that are present in the leaf extracts [34].

\subsubsection{FTIR Analysis}

Fourier transform infrared (FTIR) spectroscopy was used to evaluate chemical bonds in surface atoms and functional atoms on the surface of AgNPs [35] [36]. The capability of plant extracts to reduce $\mathrm{AgNO}_{3}$ to AgNPs is due to the presence of secondary metabolites which play the main role in changing electron charge and convert it to nano-sized particles [37]. As shown in "Figure 4" the FTIR analysis of $A$. ampeloprasum extract before and after the addition of silver 


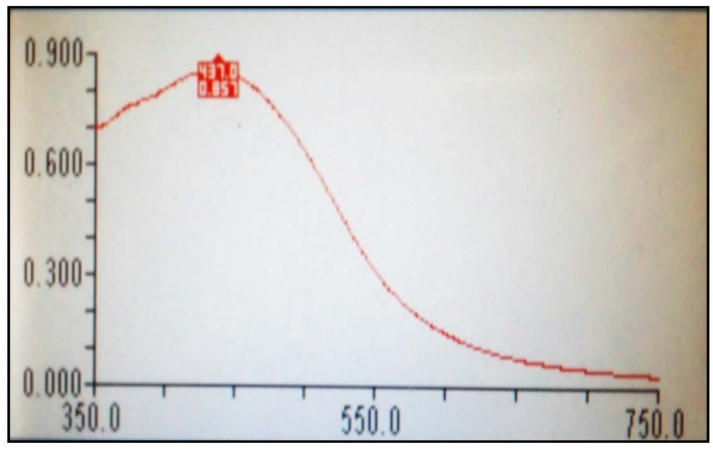

Figure 2. UV-Vis spectral analysis of Allium ampeloprasum AgNPs.
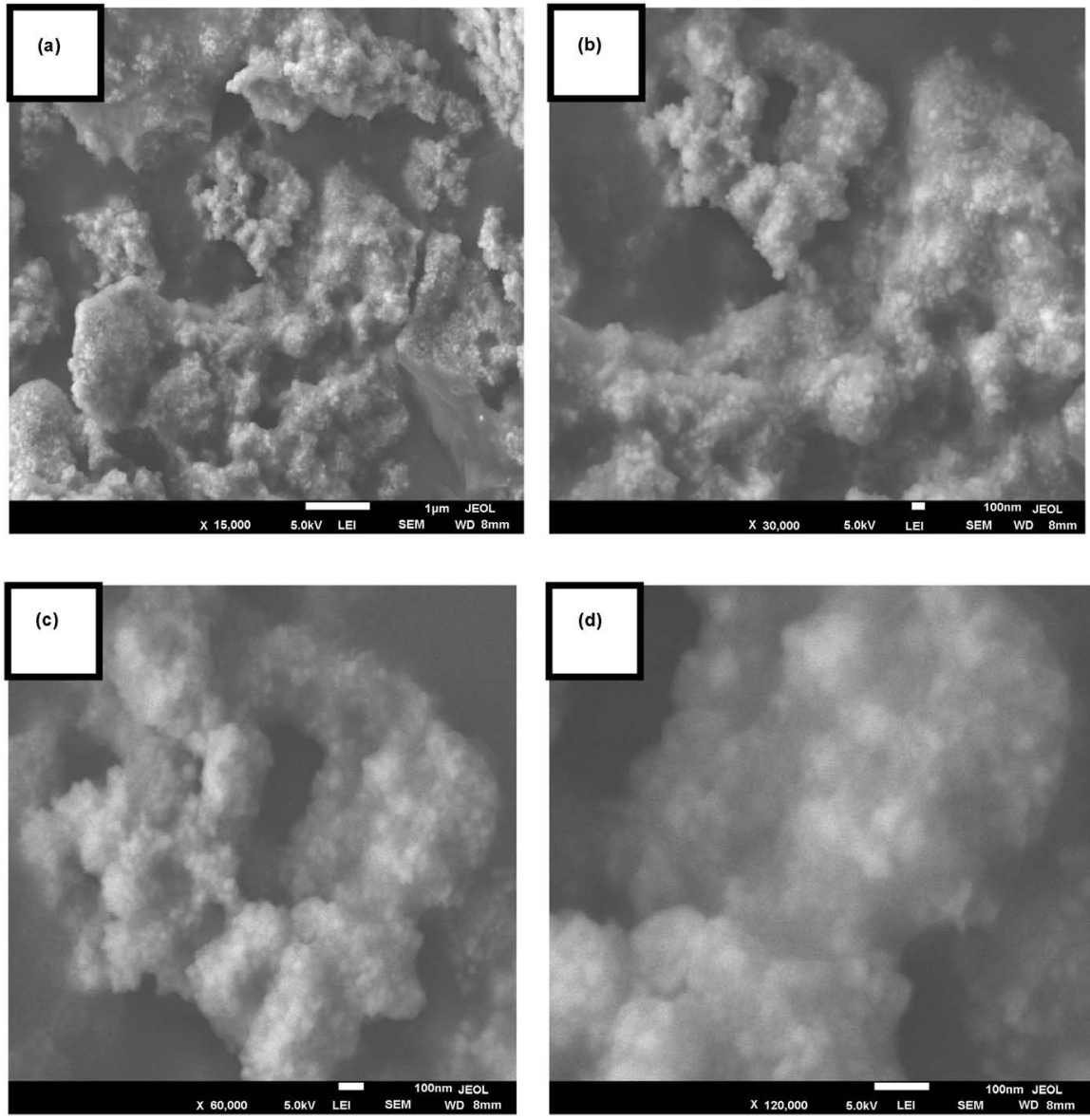

Figure 3. SEM images of $A$. ampeloprasum AgNPs at different magnifications (a) $15.000 \times$, (b) $30.000 \times$, (c) $60.000 \times$ and (d) $120.000 \times$.

nitrates, showing a decrease in some absorption peaks after the reaction at the wavelengths $3600-4000 \mathrm{~cm}^{-1}$. It is also noticed that many absorption peaks disappeared after the addition of silver nitrates at wavelengths from 2000 to 3400 $\mathrm{cm}^{-1}$. The decrease of some absorption peaks, as well as the displacement or reduction of others after the addition of silver nitrates to the plant extract is due to the interaction of reduction of nitrates group with some other extract groups 


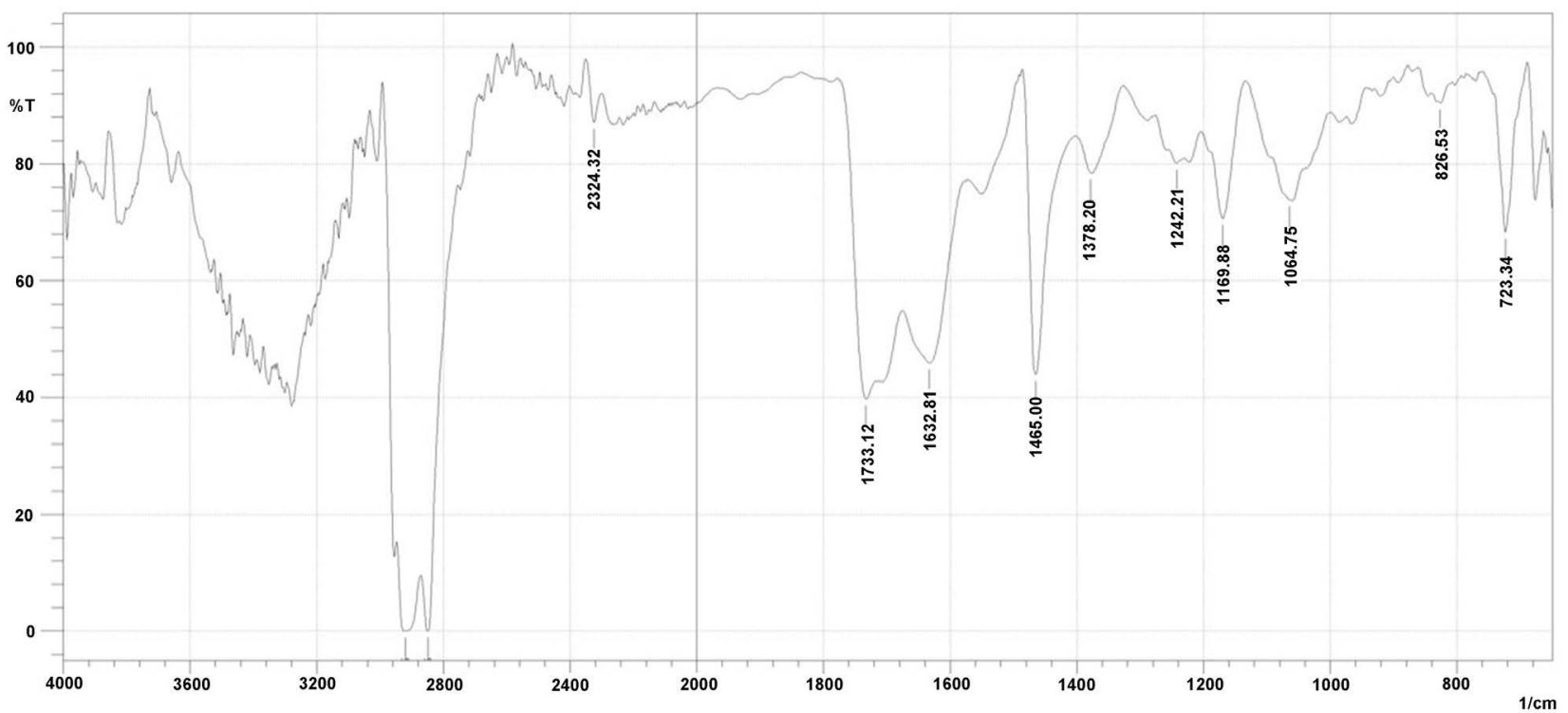

(a)

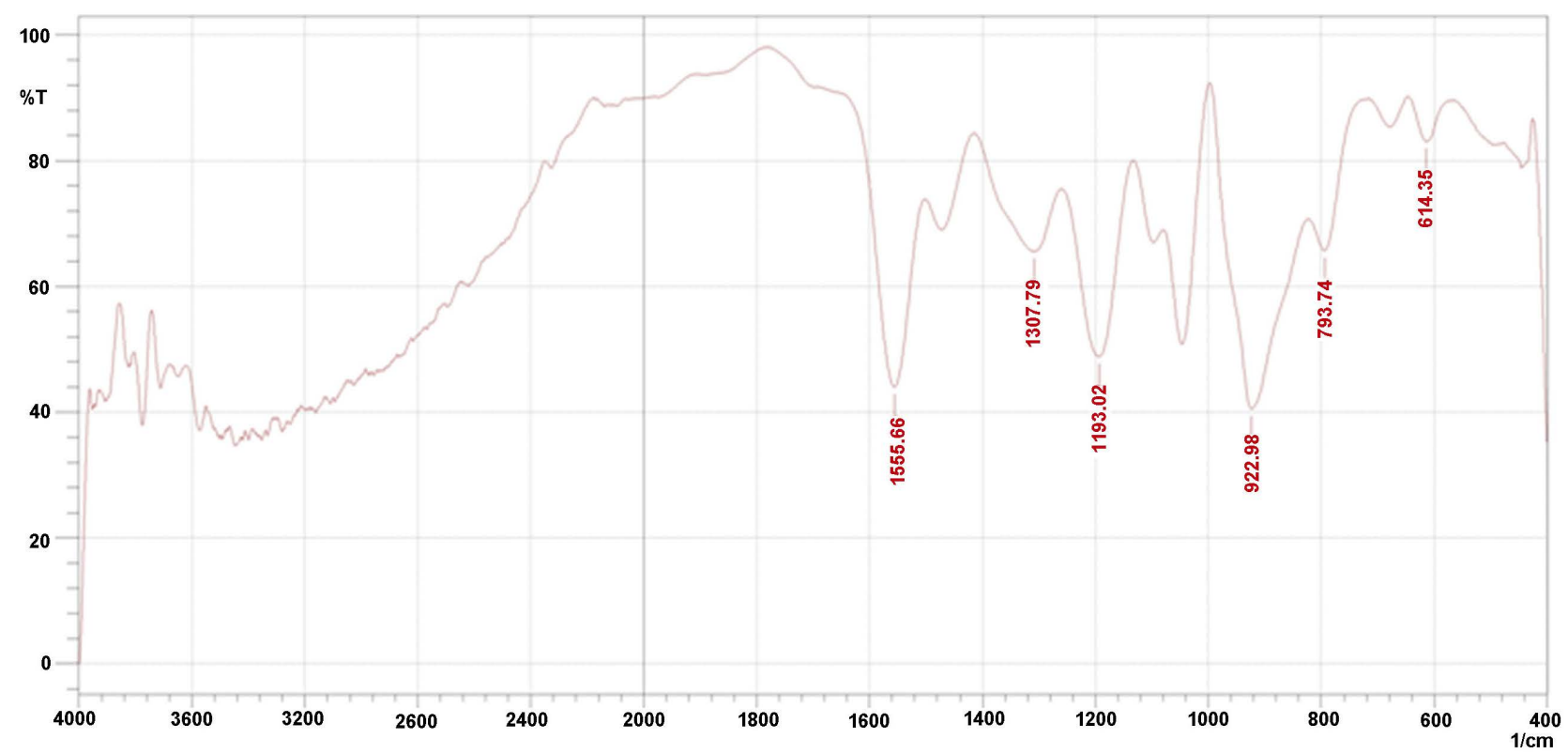

(b)

Figure 4. FTIR spectra of $A$. ampeloprasum leaves extract (a) and $A$. ampeloprasum AgNPs (b).

from carboxylic acids and the Amine group and all lead to the formation of nitric acid and silver nanoparticles formation.

Generally, FTIR results suggested that stabilization of the AgNPs may have resulted from binding of the carbonyl group of the reducing sugars to the silver [38]. Proteins may bind to AgNPs through free amine groups or carboxyl groups of amino acid residue in it. IR spectroscopic study confirmed that the plant extract can perform dual functions of reduction and stabilization of AgNPs [39]. Similar results were observed in previous study of Ricinus communis leaf extract produced AgNPs [40] and A. ampeloprasum aqueous leaf extract AgNPs [28]. 
Based on these FTIR studies, clearly reveals hydroxyl groups of phenols and amide groups of proteins from plant extract forming a layer to the nanoparticles and acting as a capping agent to prevent agglomeration and providing stability in the medium. Phenolic compounds belonging to the lignans group have been earlier reported to be capable of chelating with metallic elements to form complexes [41]. Thus, it can be concluded that hydroxyl and carboxyl groups present in phenolic compounds play a key role. These results confirm the presence of phenols and proteins which may act as reducing and stabilizing agents for silver nanoparticles and agreed with Najda et al. (2015) results of secondary metabolites and antioxidant in $A$. ampeloprasum [42].

\subsection{Antifungal Activity of AgNPs}

The AgNPs solution was screened for antifungal activity against the five fungal strains under study. AgNPs synthesized by A. ampeloprasum showed excellent antifungal against the fungal isolates. "Figure 5 and Table 1" with ZOI that ranged from $8-14 \mathrm{~mm}$ (8 mm for A. flavus1, $10 \mathrm{~mm}$ for $A$. parasiticus, $11 \mathrm{~mm}$ for A. flavus 2, $11 \mathrm{~mm}$ for $A$. ochraceus, and $14 \mathrm{~mm}$ for $A$. niger). There was no $\mathrm{ZOI}$ around the wells of $\mathrm{AgNO}_{3}$ and plant extracts and this confirmed that the inhibition was due to silver nanoparticles which exhibit good antifungal activity. The results were similar to pervious study which presented the antifungal activity of Adansonia digitata L. fruit pulp AgNPs against A. flavus and A. niger [43]. Also, agreed with the results represented the antifungal effect of AgNPs from acasia sp. against five different human pathogens $A$. niger, A. fumigatus, A. flavus, Penicillium sp. and Candidaalbicans [44]. These findings have confirmed the results that demonstrated the antifungal activity of AgNPs biosynthesized by lactic acid bacteria against spoilage fungi from genera Fusarium verticillioides, Penicillium expansum, A. flavus, and A. ochraceus [45].

The maximum inhibitory concentration of AgNPs showed significant antifungal activity against tested toxigenic species. The MIC values of $A$. ampeloprasum AgNPs was $1250 \mu \mathrm{g} / \mathrm{ml}$ for $A$. flavus 1 and A. flavus 2, $652 \mu \mathrm{g} / \mathrm{ml}$ for $A$. niger, $652 \mu \mathrm{g} / \mathrm{ml}$ for $A$. ochraceus and $2500 \mu \mathrm{g} / \mathrm{ml}$ for A. parasiticus. Till date, the AgNPs antifungal mechanism is not well explained. It was suggested that the nanoparticles can disrupt the cell membrane structure and then penetrating into the fungi which leads to the cell death [46].

\section{SEM Examination of Morphological Changes on Treated Fungi}

The SEM analysis observed the interaction between AgNPs and the membrane structure of Aspergillus species by detecting significant changes to the hyphae membranes and spores surface which form pits on their surfaces. In "Figure 6" the untreated A. flavus 1 have normal and healthy hyphae shape and spores without noticeable alteration. After exposure to AgNPs solution, A. flavus had deep craters and damaged spores were observed. The treated hyphae were almost seen like a shrunken and cropped. In "Figure 7", the untreated spores of $A$. flavus 2 had a normal and intact chain of spores with smooth walls, and the 


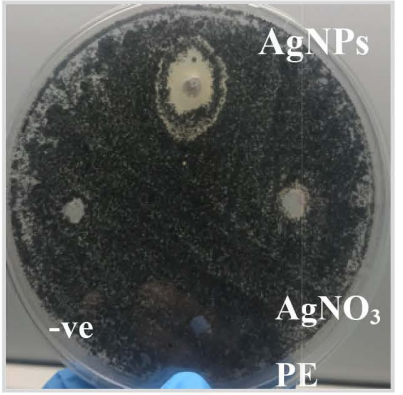

A. niger

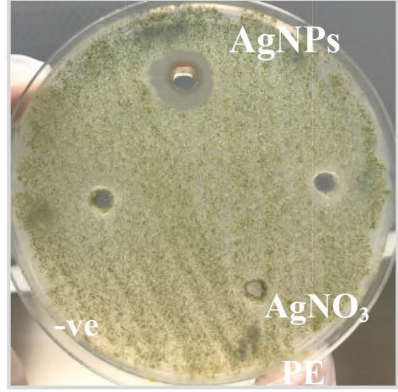

A.flavus I

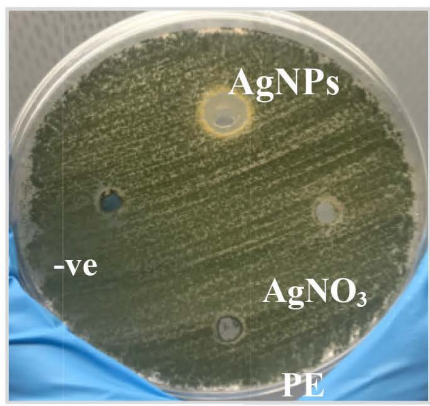

A.parasiticus

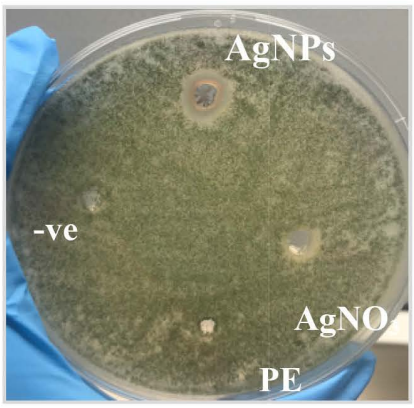

A.flavus 2

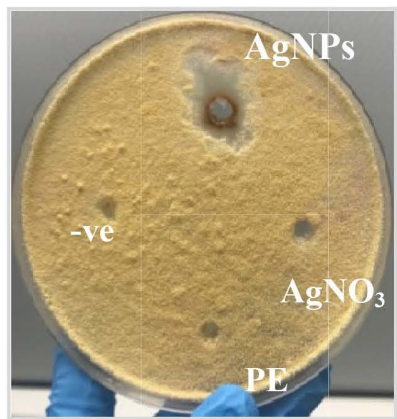

A.ochraceus

Figure 5. Antifungal activity of plant extract (PE), $\mathrm{AgNO}_{3}, \mathrm{AgNPs}$ and negative control dH2o (-ve).

Table 1. Diameter of zone of inhibition by biosynthesized AgNPs \& The minimum inhibitory concentration of AgNPs (MIC) against tested fungal isolates.

\begin{tabular}{ccc}
\hline \multirow{2}{*}{ Strains } & \multicolumn{2}{c}{ Antifungal activity } \\
\cline { 2 - 3 } & ZOI $(\mathrm{mm})$ by AgNPs $\pm \mathrm{SD}$ & $\mathrm{MIC}(\mu \mathrm{g} / \mathrm{ml})$ \\
\hline A. flavus 1 & $8.00 \pm .000$ & 1250 \\
A. flavus 2 & $10.33 \pm 2.082$ & 652 \\
A. parasiticus & $9.33 \pm 1.528$ & 2500 \\
A. ochraceus & $10.67 \pm 1.155$ & 652 \\
A. niger & $14.00 \pm 1.732$ & 652
\end{tabular}

ZOI: Zone of Inhibition expressed as mean \pm SD. 


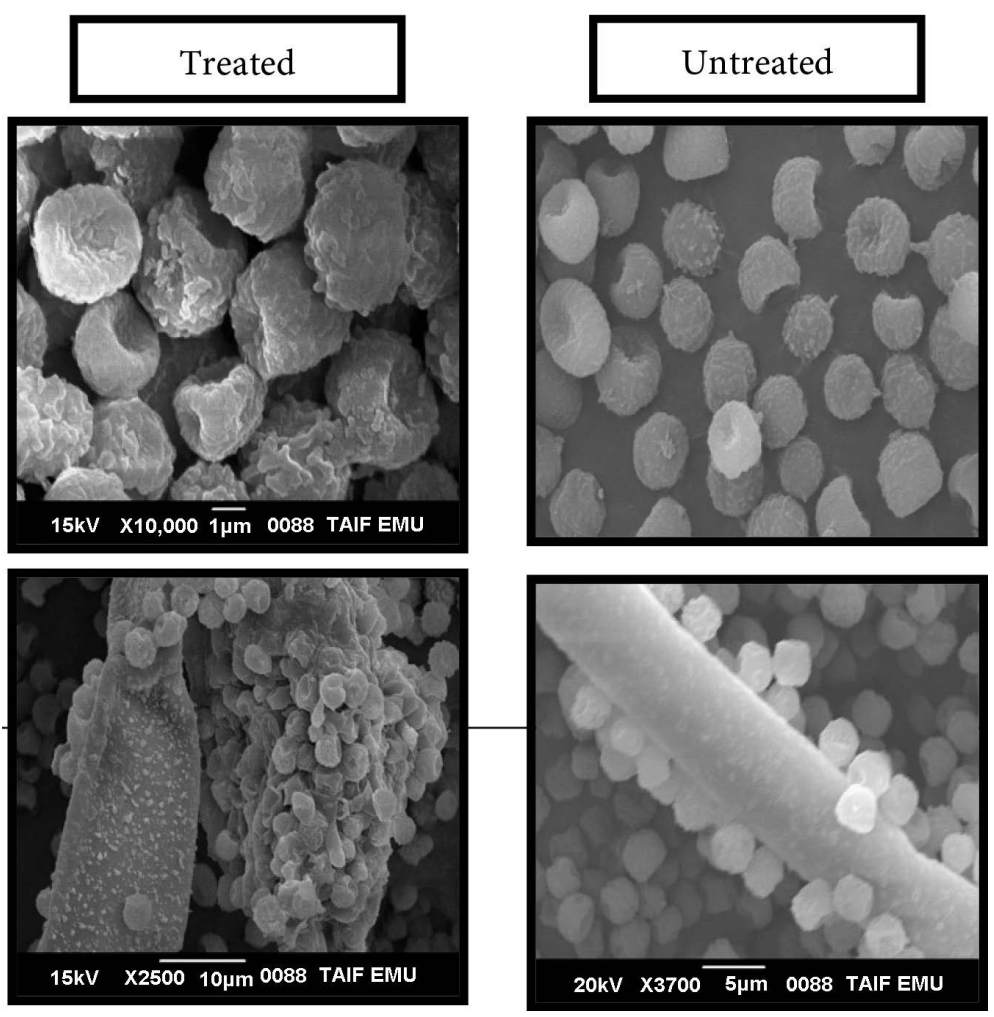

Figure 6. SEM micrographs of morphological changes on A. flavus 1 treated with $A$. ampeloprasum AgNPs and untreated.
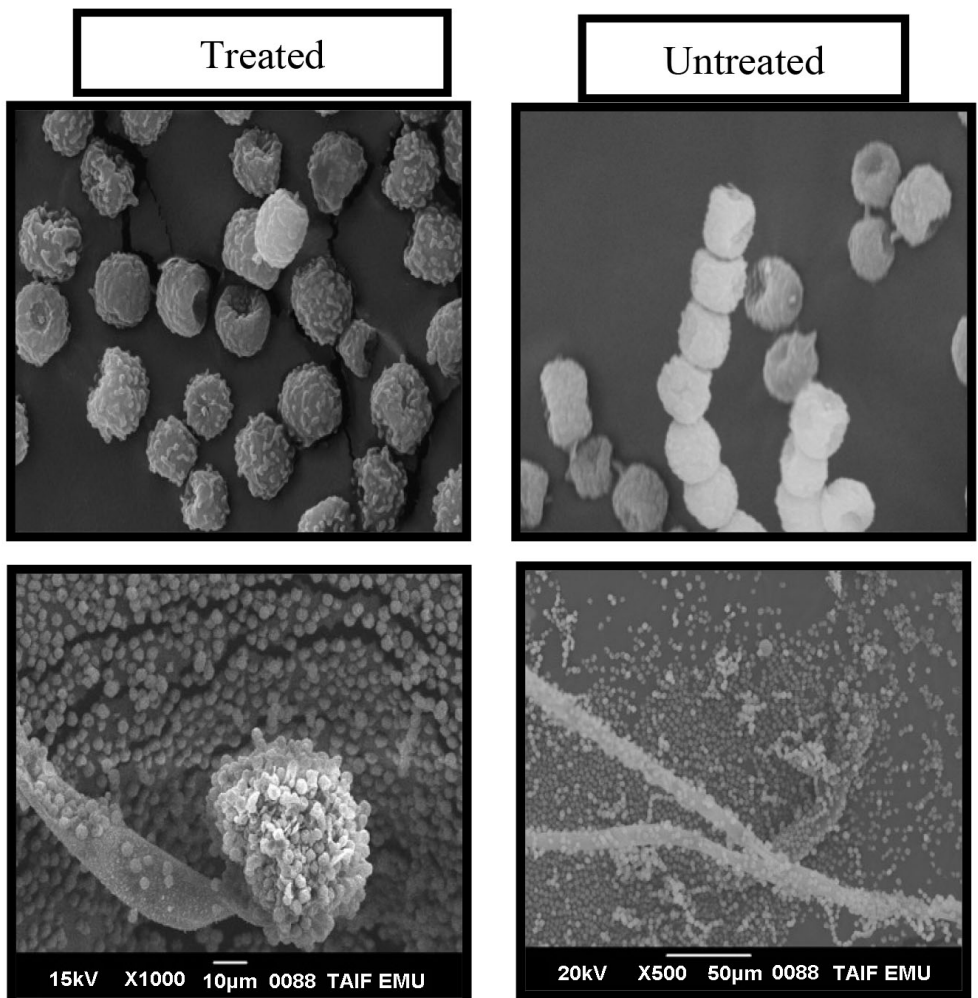

Figure 7. SEM micrographs of morphological changes on A. flavus 2 treated with A.ampeloprasum AgNPs and untreated. 
tubular hyphae were substantial and well rounded. While the treated hyphae were wrinkled, collapsed, and folded. Besides, the warty surface of the conidia was damaged and wrecked. These results came in accord with reports evaluating AgNPs capability in destroying surface membrane structure of the fungus using SEM [47]. Finally, plant extracts exhibited a potential in formation of AgNPs with potent antifungal effects on Aspergillus species tested. Therefore, it was concluded that AgNPs has considerable antifungal activity, deserving further investigation for mycotoxins control.

\section{Conclusion}

In conclusion, Methanolic extracts of Allium ampeloprasum leaves proved its potential to reduce silver ions into silver nanoparticles (AgNPs) with remarkable antifungal activity against all tested toxigenic Aspergillus species in the study. While, methanolic extract of the plant showed no antifungal effect. Thus, plant extracts can be used for rapid and eco-friendly biosynthesis of stable silver nanoparticles possessing antifungal activity suggesting their possible application in medical industry. To the best of our knowledge, this may be the first study in which $A$. ampeloprasum methanolic extract has been used to biosynthesize AgNPs and antifungal property also been observed from the synthesized nanoparticles against toxigenic fungal species.

\section{Conflicts of Interest}

The authors declare no conflicts of interest regarding the publication of this paper.

\section{References}

[1] Jarvis, B. (1975) Mycotoxins in Food-Their Occurrence and Significance. International Journal of Environmental Studies, 8, 187-194. https://doi.org/10.1080/00207237508709732

[2] Pitt, J.I., Basilico, J.C., Abarca, M.L. and Lopez, C. (2000) Mycotoxins and Toxigenic Fungi. Medical Mycology, 38, 41-46. https://doi.org/10.1080/mmy.38.s1.41.46

[3] Richard, J.L. (2007) Some Major Mycotoxins and Their Mycotoxicoses-An Overview. International Journal of Food Microbiology, 119, 3-10. https://doi.org/10.1016/j.ijfoodmicro.2007.07.019

[4] Adeyeye, S.A. (2016) Fungal Mycotoxins in Foods: A Review. Cogent Food \& Agriculture, 2, 1213127. https://doi.org/10.1080/23311932.2016.1213127

[5] Ghannoum, M.A. and Rice, L.B. (1999) Antifungal Agents: Mode of Action, Mechanisms of Resistance, and Correlation of These Mechanisms with Bacterial Resistance. Clinical Microbiology Reviews, 12, 501-517.

https://doi.org/10.1128/CMR.12.4.501

[6] Sequeira, S., Cabrita, E.J. and Macedo, M.F. (2012) Antifungals on Paper Conservation: An Overview. International Biodeterioration \& Biodegradation, 74, 67-86. https://doi.org/10.1016/j.ibiod.2012.07.011

[7] Beyth, N., Houri-Haddad, Y., Domb, A., Khan, W. and Hazan, R. (2015) Alternative Antimicrobial Approach: Nano-Antimicrobial Materials. Evidence-Based Complementary and Alternative Medicine, 2015, Article ID 246012. 
https://doi.org/10.1155/2015/246012

[8] Brandelli, A., Ritter, A.C. and Veras, F.F. (2017) Antimicrobial Activities of Metal Nanoparticles. In: Rai, M. and Shegokar, R., Eds., Metal Nanoparticles in Pharma, Springer, Cham, 337-363. https://doi.org/10.1007/978-3-319-63790-7_15

[9] Zhang, X. (2015) Gold Nanoparticles: Recent Advances in the Biomedical Applications. Cell Biochemistry and Biophysics, 72, 771-775. https://doi.org/10.1007/s12013-015-0529-4

[10] Rai, M., Ingle, A.P., Birla, S., Yadav, A. and Santos, C.A.D. (2016) Strategic Role of Selected Noble Metal Nanoparticles in Medicine. Critical Reviews in Microbiology, 42, 696-719.

[11] Ogar, A., Tylko, G. and Turnau, K. (2015) Antifungal Properties of Silver Nanoparticles against Indoor Mould Growth. Science of the Total Environment, 521, 305-314. https://doi.org/10.1016/j.scitotenv.2015.03.101

[12] Rajeshkumar, S., Malarkodi, C., Vanaja, M. and Annadurai, G. (2016) Anticancer and Enhanced Antimicrobial Activity of Biosynthesizd Silver Nanoparticles against Clinical Pathogens. Journal of Molecular Structure, 1116, 165-173.

https://doi.org/10.1016/j.molstruc.2016.03.044

[13] Davidson, P.M. (2001) Chemical Preservatives and Naturally Antimicrobial Compounds. In: Doyle, M.P., Beuchat, L.R. and Montville, T.J., Eds., Food Microbiology: Fundamentals and Frontiers, 2nd Edition, American Society for Microbiology Press, Washington DC, 593-628.

[14] Ahmed, S., Ahmad, M., Swami, B.L. and Ikram, S. (2016) A Review on Plants Extract Mediated Synthesis of Silver Nanoparticles for Antimicrobial Applications: A Green Expertise. Journal of Advanced Research, 7, 17-28. https://doi.org/10.1016/j.jare.2015.02.007

[15] Eidi, M., Eidi, A. and Zamanizadeh, H. (2005) Effect of Salvia officinalis L. Leaves on Serum Glucose and Insulin in Healthy and Streptozotocin-Induced Diabetic Rats. Journal of Ethnopharmacology, 100, 310-313. https://doi.org/10.1016/j.jep.2005.03.008

[16] Khan, J.A. and Hanee, S. (2011) Antibacterial Properties of Punica granatum Peels. International Journal of Applied Biology and Pharmaceutical Technology, 2, 23-27.

[17] Naik, B.R., Gowreeswari1, G.S., Singh, Y., Satyavathi, R., Daravath, S.S. and Reddy, P.R. (2014) Bio-Synthesis of Silver Nanoparticles from Leaf Extract of Pongamia pinnata as an Effective Larvicide on Dengue Vector Aedes albopictus (Skuse) (Diptera: Culicidae). Advances in Entomology, 2, 93-101. https://doi.org/10.4236/ae.2014.22016

[18] Satyavani, K., Ramanathan, T. and Gurudeeban, S. (2011) Plant Mediated Synthesis of Biomedical Silver Nanoparticles by Using Leaf Extract of Citrullus colocynthis. Research Journal of Nanoscience and Nanotechnology, 1, 95-101. https://doi.org/10.3923/rjnn.2011.95.101

[19] Magaldi, S., Mata-Essayag, S., De Capriles, C.H., Perez, C., Colella, M.T., Olaizola, C. and Ontiveros, Y. (2004) Well Diffusion for Antifungal Susceptibility Testing. International Journal of Infectious Diseases, 8, 39-45. https://doi.org/10.1016/j.ijid.2003.03.002

[20] Valgas, C., Souza, S.M.D., Smânia, E.F. and Smânia Jr., A. (2007) Screening Methods to Determine Antibacterial Activity of Natural Products. Brazilian Journal of Microbiology, 38, 369-380. https://doi.org/10.1590/S1517-83822007000200034

[21] Bonnavero, V., Chevaleier, J. and Cremieux, A. (1988) A Rapid Method Outoma- 
tized Method for Assyment of the Fungal Activity of Natural and Synthetic Agents. 6th Mediterranean Congress of Chemotherapy, Taormina, 22-27 May 1988, 22-27.

[22] Ouda, S.M. (2014) Antifungal Activity of Silver and Copper Nanoparticles on Two Plant Pathogens, Alternaria alternata and Botrytis cinerea. Research Journal of Microbiology, 9, 34-42. https://doi.org/10.3923/jm.2014.34.42

[23] Veerakumar, K., Govindarajan, M. and Rajeswary, M. (2013) Green Synthesis of Silver Nanoparticles Using Sida acuta (Malvaceae) Leaf Extract against Culex quinquefasciatus, Anopheles stephensi, and Aedes aegypti (Diptera: Culicidae). Parasitology Research, 112, 4073-4085. https://doi.org/10.1007/s00436-013-3598-6

[24] Vanaja, M., Gnanajobitha, G., Paulkumar, K., Rajeshkumar, S., Malarkodi, C. and Annadurai, G. (2013) Phytosynthesis of Silver Nanoparticles by Cissus quadrangularis. Influence of Physicochemical Factors. Journal of Nanostructure in Chemistry, 3, 17. https://doi.org/10.1186/2193-8865-3-17

[25] Halawani, E.M. (2016) Rapid Biosynthesis Method and Characterization of Silver Nanoparticles Using Zizyphus spina christi Leaf Extract and Their Antibacterial Efficacy in Therapeutic Application. Journal of Biomaterials and Nanobiotechnology, 8, 22. https://doi.org/10.4236/jbnb.2017.81002

[26] Ravichandran, V., Vasanthi, S., Shalini, S., Shah, S.A.A. and Harish, R. (2016) Green Synthesis of Silver Nanoparticles Using Atrocarpus altilis Leaf Extract and the Study of Their Antimicrobial and Antioxidant Activity. Materials Letters, 180, 264-267. https://doi.org/10.1016/j.matlet.2016.05.172

[27] Sre, P.R., Reka, M., Poovazhagi, R., Kumar, M.A. and Murugesan, K. (2015) Antibacterial and Cytotoxic Effect of Biologically Synthesized Silver Nanoparticles Using Aqueous Root Extract of Erythrina indica Lam. Spectrochimica Acta Part A: Molecular and Biomolecular Spectroscopy, 135, 1137-1144. https://doi.org/10.1016/j.saa.2014.08.019

[28] Khoshnamvand, M., Huo, C. and Liu, J. (2019) Silver Nanoparticles Synthesized Using Allium ampeloprasum L. Leaf Extract: Characterization and Performance in Catalytic Reduction of 4-Nitrophenol and Antioxidant Activity. Journal of Molecular Structure, 1175, 90-96. https://doi.org/10.1016/j.molstruc.2018.07.089

[29] Sastry, M., Mayya, K.S. and Bandyopadhyay, K. (1997) pH Dependent Changes in the Optical Properties of Carboxylic Acid Derivatized Silver Colloidal Particles. Colloids and Surfaces A: Physicochemical and Engineering Aspects, 127, 221-228. https://doi.org/10.1016/S0927-7757(97)00087-3

[30] Henglein, A. (1993) Physicochemical Properties of Small Metal Particles in Solution: "Microelectrode" Reactions, Chemisorption, Composite Metal Particles, and the Atom-to-Metal Transition. The Journal of Physical Chemistry, 97, 5457-5471. https://doi.org/10.1021/j100123a004

[31] Swamy, M.K., Akhtar, M.S., Mohanty, S.K. and Sinniah, U.R. (2015) Synthesis and Characterization of Silver Nanoparticles Using Fruit Extract of Momordica cymbalaria and Assessment of Their in Vitro Antimicrobial, Antioxidant and Cytotoxicity Activities. Spectrochimica Acta Part A: Molecular and Biomolecular Spectroscopy, 151, 939-944. https://doi.org/10.1016/j.saa.2015.07.009

[32] Johnson, I. and Prabu, H.J. (2015) Green Synthesis and Characterization of Silver Nanoparticles by Leaf Extracts of Cycas circinalis, Ficus amplissima, Commelina benghalensis and Lippianodiflora. International Nano Letters, 5, 43-51. https://doi.org/10.1007/s40089-014-0136-1

[33] De Soyza, S.G., Wijayaratne, W.M.D.G.B., Napagoda, M. and Witharana, S. (2017) Antimicrobial Potential in Biogenic Silver Nanoparticles Synthesized from Plec- 
tranthus zeylanicus. Journal of Molecular Nanotechnology and Nanomedicine, 1 , 105.

[34] Krithiga, J. and Briget, M.M. (2015) Synthesis of Agnps of Momordica charantia Leaf Extract, Characterization and Antimicrobial Activity. Pharmaceutica Analytica Acta, 6, 427.

[35] Morais, P.C., Santos, R.L., Pimenta, A.C.M., Azevedo, R.B. and Lima, E.C.D. (2006) Preparation and Characterization of Ultra-Stable Biocompatible Magnetic Fluids Using Citrate-Coated Cobalt Ferrite Nanoparticles. Thin Solid Films, 515, 266-270. https://doi.org/10.1016/j.tsf.2005.12.079

[36] Chung, I.M., Park, I., Seung-Hyun, K., Thiruvengadam, M. and Rajakumar, G. (2016) Plant-Mediated Synthesis of Silver Nanoparticles: Their Characteristic Properties and Therapeutic Applications. Nanoscale Research Letters, 11, 40. https://doi.org/10.1186/s11671-016-1257-4

[37] Makarov, V.V., Love, A.J., Sinitsyna, O.V., Makarova, S.S., Yaminsky, I.V., Taliansky, M.E. and Kalinina, N.O. (2014) “Green” Nanotechnologies: Synthesis of Metal Nanoparticles Using Plants. Acta Naturae, 6, 20.

[38] Venu, R., Ramulu, T.S., Anandakumar, S., Rani, V.S. and Kim, C.G. (2011) Bio-Directed Synthesis of Platinum Nanoparticles Using Aqueous Honey Solutions and Their Catalytic Applications. Colloids and Surfaces A: Physicochemical and Engineering Aspects, 384, 733-738. https://doi.org/10.1016/j.colsurfa.2011.05.045

[39] Sharma, G., Sharma, A.R., Kurian, M., Bhavesh, R., Nam, J.S. and Lee, S.S. (2014) Green Synthesis of Silver Nanoparticles Using myristica fragrans (Nutmeg) Seed Extract and Its Biological Activity. Digest Journal of Nanomaterials \& Biostructures, 9, 325-332.

[40] Ojha, S., Sett, A. and Bora, U. (2017) Green Synthesis of Silver Nanoparticles by Ricinus communis var. carmencita Leaf Extract and Its Antibacterial Study. Advances in Natural Sciences: Nanoscience and Nanotechnology, 8, Article ID: 035009. https://doi.org/10.1088/2043-6254/aa724b

[41] Chatterjee, S., Niaz, Z., Gautam, S., Adhikari, S., Variyar, P.S. and Sharma, A. (2007) Antioxidant Activity of Some Phenolic Constituents from Green Pepper (Piper nigrum L.) and Fresh Nutmeg Mace (Myristica fragrans). Food Chemistry, 101, 515-523. https://doi.org/10.1016/j.foodchem.2006.02.008

[42] Najda, A., Błaszczyk, L., Winiarczyk, K., Dyduch, J. and Tchórzewska, D. (2016) Comparative Studies of Nutritional and Health-Enhancing Properties in the "Garlic-Like" Plant Allium ampeloprasum var. Ampeloprasum (GHG-L) and A. sativum. Scientia Horticulturae, 201, 247-255. https://doi.org/10.1016/j.scienta.2016.01.044

[43] Kumar, C.M.K., Yugandhar, P. and Savithramma, N. (2016) Biological Synthesis of Silver Nanoparticles from Adansonia digitata L. Fruit Pulp Extract, Characterization, and Its Antimicrobial Properties. Journal of Intercultural Ethnopharmacology, 5,79 .

[44] Balashanmugam, P., Balakumaran, M.D., Murugan, R., Dhanapal, K. and Kalaichelvan, P.T. (2016) Phytogenic Synthesis of Silver Nanoparticles, Optimization and Evaluation of in Vitro Antifungal Activity against Human and Plant Pathogens. Microbiological Research, 192, 52-64. https://doi.org/10.1016/j.micres.2016.06.004

[45] Matei, A., Cornea, C.P., Matei, S., Matei, G.M., Cogălniceanu, G. and Rodino, S. (2015) Biosynthesis of Silver Nanoparticles Using Culture Filtrates of Lactic Acid Bacteria and Analysis of Antifungal Activity. Digest Journal of Nanomaterials and Biostructures, 10, 1201-1207. 
[46] Krishnaraj, C., Jagan, E.G., Ramachandran, R., Abirami, S.M., Mohan, N. and Kalaichelvan, P.T. (2012) Effect of Biologically Synthesized Silver Nanoparticles on Bacopa monnieri (Linn.) Wettst. Plant Growth Metabolism. Process Biochemistry, 47, 651-658. https://doi.org/10.1016/j.procbio.2012.01.006

[47] Alt, V., Bechert, T., Steinrücke, P., Wagener, M., Seidel, P., Dingeldein, E., Schnettler, R., et al. (2004) An in Vitro Assessment of the Antibacterial Properties and Cytotoxicity of Nanoparticulate Silver Bone Cement. Biomaterials, 25, 4383-4391.

https://doi.org/10.1016/j.biomaterials.2003.10.078 